\title{
A RENDA FUNDIÁRIA URBANA: UMA CATEGORIA DE ANÁLISE AINDA VÁLIDA
}

\author{
ADRIANO BOTELHO ${ }^{1}$
}

Doutor em Geografia Humana pela FFLCH - USP

\section{Introdução}

Pode-se afirmar com certa segurança que a questão da renda fundiária urbana foi quase que abandonada por grande parte do meio acadêmico a partir do final da década de $1980^{2}$. Tal situação contrasta com o período compreendido entre o final dos anos 70 do século XX e início da década de 1980, quando os estudos sobre a renda fundiária urbana apresentaram grande importância no âmbito do esforço de compreensão não só do urbano como do próprio processo de reprodução do capital naquele momento histórico. Entre os autores que trataram esta temática pode-se citar os trabalhos de Lipietz (1974), Lojkine (1971, 1997), Alquier (1971), Fine (1988), Harvey (1980, 1990), Seabra (1987, 1988), Topalov $(1984)^{3}$. Buscou-se, dessa forma, adaptar as teorias de Marx ao contexto

${ }^{1}$ Este artigo tem sua origem nas pesquisas desenvolvidas para a Tese de Doutorado $O$ financiamento e a financeirização do setor imobiliário: Uma análise da produção do espaço e da segregação sócio-espacial na cidade de São Paulo através do estudo do mercado da moradia, defendida em Setembro de 2005 sob orientação da Prof. Dra. Margarida Maria de Andrade, a quem aproveito a oportunidade para agradecer o apoio constante. A Tese contou com Bolsa de Auxilio da Fapesp.

${ }^{2}$ Devemos fazer justiça a alguns pesquisadores que mais recentemente têm contemplado a questão da renda fundiária urbana em seus trabalhos, como Pedro Abramo, Fernanda Furtado, Oscar Alfonso, Sérgio Martins e Aluísio Wellichan Ramos. Também é importante lembrar a contribuição dada por Luiz Cesar de Queiroz Ribeiro, Tamara Cohen Egler e Martim Smolka entre as décadas de 1980 e meados da década de 1990.

${ }^{3}$ Um autor que em suas obras chamou atenção para a importância da propriedade fundiária e para a renda fundiária urbana, sem, contudo, realizar estudos exclusivos e exaustivos sobre essa temática foi Henri Lefebvre. Seus estudos mais aprofundados sobre a renda fundiária se ligaram ao meio rural; ver, por exemplo, Lefebvre, 1978. Na mesma época, contribuição fundamental para a compreensão da renda fundiária no campo e suas articulações com o modo de produção capitalista foi dada por José de Souza Martins (1996). E também há uma série de artigos de Ariovaldo U. de Oliveira (1984, 1985, 1986) 
urbano do pós-II Guerra Mundial nos países mais ricos e em alguns casos de países "em desenvolvimento". Porém, a quase totalidade destes autores acabou por abandonar os trabalhos sobre a renda fundiária urbana. Por quê?

Não há condições no presente trabalho de dar uma resposta a essa questão, pois seria necessária uma outra pesquisa que buscasse elucidar as causas de seu relativo abandono. Deve-se ter em conta, porém, que o estudo da renda fundiária urbana enfrenta uma série de problemas, tanto de ordem teórico-metodológica, quanto de ordem prática. As dificuldades para a coleta de dados para o cálculo da renda fundiária em grandes cidades e para a identificação dos proprietários fundiários urbanos, por exemplo, ilustram os sérios problemas enfrentados pelo pesquisador quando se debruça sobre a questão.

Porém, tal questão, longe de ser ultrapassada ou ter sido esgotada, oferece uma possibilidade de abordagem do urbano que permite a análise de fenômenos importantes, como a hierarquização dos usos do solo, o papel do setor imobiliário para a acumulação do capital e para a reprodução das relações de produção capitalistas, além de ser um importante instrumento para o entendimento do processo de segregação sócio-espacial e fragmentação do espaço no urbano. Assim, levando-se em consideração os estudos passados e as dificuldades que ainda hoje permanecem, a questão da renda fundiária é retomada no presente artigo.

Como forma de viabilização da análise da questão da renda fundiária urbana, tendo em vista as dificuldades práticas já mencionadas, foi realizado um estudo de caso sobre uma modalidade de intervenção no urbano por parte do setor imobiliário em aliança com o mercado financeiro na cidade de São Paulo: os Fundos de Investimento Imobiliário e a Securitização de Recebíveis Imobiliários.

Dessa forma, o presente artigo tem por objetivo analisar como a renda fundiária se insere no processo de reprodução do capital em suas tramas com a produção do espaço urbano. A primeira parte traz algumas considerações teóricas sobre a questão da renda fundiária urbana. A segunda parte trata dos Fundos de Investimento Imobiliário e da Securitização de Recebíveis Imobiliários. $\mathrm{Na}$ terceira parte são estabelecidas algumas relações entre o caso analisado na parte anterior e a questão da renda imobiliária. E a quarta parte consiste nas considerações finais.

sobre a renda da terra. 


\section{A renda fundiária urbana}

Segundo Marx (1989), toda a renda fundiária capitalista é mais-valia, produto de trabalho excedente não pago a quem produziu, e não uma propriedade inerente ao solo. Ou seja, a renda fundiária é uma parcela do excedente global produzido pela classe trabalhadora e que é apropriado pela classe dos proprietários fundiários, devido ao monopólio que exercem sobre a propriedade da terra. Em sua análise sobre a questão, Marx dividiu a renda fundiária capitalista em três: renda absoluta, renda diferencial (I e II) e renda de monopólio ${ }^{4}$.

A renda da terra possui o seu correspondente na cidade, e ainda que nas aglomerações urbanas a renda fundiária não apareça diretamente, ela está incluída no aluguel dos escritórios, das moradias etc. ou no preço cobrado pelos imóveis (ALQUIER, 1971). A renda da terra perde sua forma concreta que tinha sob a agricultura (renda em trabalho, em espécie ou dinheiro); ela assume uma forma abstrata: a renda não se apresenta mais como um produto do solo, ela aparece como nada mais do que o juro de um capital investido.

Marx, ainda que de forma resumida, analisou o papel da renda nos terrenos urbanos para construção, sendo que ela se caracterizaria: 1) pela influência decisiva da localização sobre a renda diferencial; 2) pela exploração pelo proprietário do progresso do desenvolvimento social para o qual nada contribui e no qual nada arrisca; 3) pelo predomínio do preço de monopólio (MARX, 1989). A renda fundiária urbana seria elevada pelo rápido e intenso crescimento da população nas grandes cidades, e pela conseqüente necessidade crescente de habitações daí resultante e também pela implementação do capital fixo que se incorporaria à terra (como edifícios, ferrovias, rodovias, armazéns, estabelecimentos fabris e comerciais, docas etc.). Nas cidades de grande crescimento, o que constituiria o objeto principal de especulação no setor imobiliário não seria o imóvel construído, mas a renda fundiária cobrada pelos proprietários (MARX, 1989).

Henri Lefebvre (1999), retomando a teoria da renda da terra desenvolvida por Marx, considerou a existência de "rendas urbanas", assemelhadas às rendas rurais fundiárias - a renda de situação (renda diferencial I) e a renda de equipamento (renda diferencial II), somando-se a elas a renda absoluta, pretendida por todo proprietário, pelo fato de ser

\footnotetext{
${ }^{4}$ Para uma análise detalhada da questão da renda fundiária capitalista em geral ver Oliveira (1984, 1984 e 1986).
} 
proprietário e que serve de base à especulação. Além destas, haveria também a renda de monopólio.

A produção capitalista de construções engendraria, nas relações de produção dominantes na cidade moderna, um sobrelucro setorial constituído pelo excedente do seu valor sobre o preço de produção das construções (TOPALOV, 1984; LOJKINE, 1971; LIPIETZ, 1974). O sobrelucro transforma-se em renda quando algumas das condições de valorização dos capitais não são reproduzíveis, sendo, portanto, monopolizáveis pelos proprietários (TOPALOV, 1979). Tal é o caso do solo urbano, uma condição de produção da indústria da construção civil, mas cujas características não podem ser reproduzidas por esta, estando seu controle nas mãos dos proprietários imobiliários.

Dentre os fatores que podem contribuir para alterações no preço cobrado pelos terrenos urbanos, haveria os fatores ligados diretamente às condições do ambiente (natural ou construído) com o qual se articula o terreno (fatores físicos, acessibilidade aos serviços locais, meio ambiente natural, vizinhança etc.); os fatores que atuariam no conjunto da zona homogênea onde o terreno estaria localizado, responsáveis pela formação do preço da terra em cada zona da cidade (posição da zona em relação aos diversos centros da cidade, ligação com o sistema de transporte, regulamentação urbanística determinando tipos e formas de uso do solo); e fatores mais gerais, que influenciariam a formação dos preços fundiários no conjunto da sociedade (ritmo de crescimento da população, conjuntura econômica, estrutura de propriedade etc.) (Granelle apud RIBEIRO, 1997).

Em uma cidade, algumas áreas destacam-se por elementos físicos e pela existência de uma melhor localização em relação aos centros de consumo, de empregos, de informações e decisões. Como uma unidade imobiliária é um valor de uso complexo, articulado no espaço com diversos valores de uso simples (equipamentos coletivos, meios de transportes etc.), a reprodutibilidade de uma determinada localização privilegiada no espaço urbano é muito difícil para o capital imobiliário, sendo praticamente impossível para um capitalista isolado reproduzir as melhores condições existentes na cidade para um empreendimento que não conta com uma localização privilegiada. Dessa forma, algumas parcelas do solo urbano tornam-se não-reprodutíveis numa escala comparável aos solos agrícolas especiais geradores de rendas de monopólio. Trata-se, nesse caso, da segunda natureza que, no meio urbano, dada a sua complexidade, cria áreas exclusivas nas quais seus consumidores estão dispostos a pagar uma renda de monopólio para poderem aí se localizar, seja em função do status que tal 
localização pode conferir ao seu usuário, seja em função de um acesso privilegiado às centralidades do urbano etc.

A diferenciação das distintas formas de renda no meio urbano é uma outra dificuldade para o pesquisador. $\mathrm{Na}$ verdade as rendas diferenciais (I e II) não seriam facilmente dissociadas entre si, da mesma maneira que a diferença entre a renda de monopólio e a renda absoluta seria de difícil identificação em alguns casos (como no caso de edifícios que possuem vistas privilegiadas, melhor insolação, regulamentação favorável, acesso a certas centralidades etc.). E as transformações na técnica da construção civil também podem mudar as relações entre as formas de renda, através da possibilidade de uso de terrenos antes não aproveitados pelos construtores.

No meio urbano, a renda da terra pode assumir a forma do preço da terra (renda capitalizada) ou pode estar inserida no aluguel cobrado dos inquilinos (residenciais, comerciais, financeiros etc.). Engels, em 1872 (ENGELS, 1979), já distinguia, no preço do aluguel, a renda da terra, o juro do capital investido na construção (compreendendo este o lucro do empreiteiro), a soma destinada a cobrir gastos em reparos e seguros e as anuidades que amortizariam o capital investido, proporcionalmente à deterioração gradual do imóvel. A concessão de serviços públicos (água, luz, saneamento) e de terrenos para a prestação de serviços (transporte) também seria uma forma de cobrança de renda fundiária pelo poder público.

Assim, um importante agente de influência no mercado imobiliário urbano é o Estado, pois através de suas ações e regulamentações interfere ativamente no que se refere ao preço da terra e à sua valorização. A localização de infra-estrutura e de equipamentos de uso coletivo sob sua responsabilidade, as leis de zoneamento, os planos de "revitalização urbana" de certas áreas da cidade, o fornecimento de financiamento para a compra da moradia e a produção da moradia pelo poder público são alguns dos exemplos de como o Estado tem um papel ativo para a formação da renda fundiária urbana, como se verá a seguir.

Segundo Topalov, os "belos bairros" das camadas superiores não o são somente nas representações coletivas, mas também na materialidade dos meios de consumo que estão disponíveis; os privilégios espaciais estão relacionados com a oferta de equipamentos urbanos (TOPALOV, 1984). Dessa forma, o espaço das camadas superiores é objetivamente diferente. Essas diferenças resultam dos processos de produção material: predomínio massivo das formas mais capitalistas de construção das habitações, privilégios por longos períodos em matéria de infra-estruturas e de 
equipamentos públicos de consumo coletivo, concentração "espontânea" dos serviços requeridos por uma clientela altamente solvente em termos monetários. Esses processos tendem, pelo jogo dos preços, a operar a segregação e hierarquização espacial que requer a legibilidade simbólica dos espaços. A concentração espacial das camadas superiores opera uma transformação qualitativa de conteúdo dos equipamentos públicos e dos equipamentos comerciais privados, tornando-os mais seletivos. A especificidade do espaço das camadas superiores é signo de distinção social, participa do sistema de expressão e de reiteração simbólica da hierarquia das situações de classe. As camadas superiores e as camadas populares passam a ter uma tendência de se excluírem no espaço urbano.

A propriedade da terra se coloca, assim, como um obstáculo frente à livre circulação do capital, tratando-se de uma contradição que antepõe a terra ao capital (MARTINS, 1983). Pois quando o capitalista paga uma renda pela utilização da terra, ele estaria, na verdade, convertendo uma parte de seu capital em renda, imobilizando improdutivamente essa parte do capital. Mas isso não significa que a apropriação da terra pelo capital impeça a sua utilização segundo critérios capitalistas.

Como o capitalista transpõe esse obstáculo representado pela renda? São diversas as formas de incorporar a propriedade e a renda fundiária à acumulação capitalista. Uma delas é a união da figura do capitalista com a figura do proprietário, o que, porém, não resolve a contradição entre terra e capital (MARTINS, 1983). Outra maneira de incorporar a renda fundiária à circulação capitalista se dá através do mercado financeiro, com a transformação da propriedade da terra em um título comercializável e alienável através de empréstimos e hipotecas. Dessa forma, a terra passa a ser um "puro bem financeiro" (HARVEY, 1990:350), e seus títulos de propriedade são vistos, segundo os que os transacionam, como um capital fictício, pois significam um direito sobre utilidades futuras sobre o uso da terra, um direito à apropriação de uma fração da mais-valia gerada por um trabalho futuro. Assim, a terra e o ambiente construído podem formar parte do capital fixo, o que não os impede de circular como valor. A propriedade fundiária e a renda que seu proprietário tem o direito de extrair da maisvalia global tornam-se, assim, elementos constituintes da acumulação capitalista, seja através da especulação e incorporação imobiliária, seja através da circulação da renda capitalizada no mercado financeiro (hipotecas e títulos imobiliários).

Por outro lado, a renda fundiária e a propriedade, além de serem um obstáculo à livre circulação do capital, também são um obstáculo à propriedade social de um dos mais importantes meios de produção (a 
terra), contribuindo assim para a contínua reprodução da classe dos que não possuem os meios de subsistência e que têm de vender sua força de trabalho para reproduzir-se (proletariado). Ou seja, é ao mesmo tempo obstáculo à livre aplicação do capital e à sua reprodução ampliada e meio de acumulação do capital, e uma das condições para a reprodução das relações de produção capitalistas.

No próximo item, será analisado um caso de incorporação da renda fundiária ao circuito de reprodução do capital: os Fundos de Investimento Imobiliário (FIIs) e os Certificados de Recebíveis Imobiliários (CRIs)

\section{Fundos de Investimento Imobiliário (FIls) e Certificados de Recebíveis Imobiliários (CRIs)}

A união do capital financeiro com o imobiliário é a principal forma de garantir fluxos de recursos para o financiamento da produção, dado o longo tempo de rotação do capital no setor imobiliário, pois o financiamento da produção e do consumo imobiliários abrevia o tempo de giro do capital na produção e reduz o tempo de sua rotação.

A produção de um imóvel por um empresário é orientada para o mercado e tem por objetivo a reprodução do capital e a remuneração dos fatores utilizados no seu processo de produção. Algumas características do setor imobiliário fazem esse setor ser muito dependente das fontes de financiamento para viabilizar a reprodução do capital empregado: a necessidade de recursos volumosos para a compra de materiais, quase sempre bens intermediários duráveis; para o pagamento da força de trabalho (parte dela qualificada, como engenheiros); para a adequação às inovações tecnológicas (particularmente sensível na construção de imóveis comerciais); e para o acesso ao solo urbano. Esses fatores têm por conseqüência que o aporte inicial de capital para a construção capitalista de imóveis seja elevado, superando muitas vezes a capacidade de investimento dos empresários do setor. Daí a necessidade de créditos para as obras ser fundamental.

Por outro lado, a demanda desse setor se encontra fragmentada entre os diversos usos a que se destina a produção imobiliária e as diversas faixas de renda da população que procura um imóvel para morar. 
A despeito de uma série de alternativas encontradas ao logo do tempo para a obtenção desse financiamento por parte do sistema financeiro (caixas de aposentadorias, cooperativas habitacionais, consórcios imobiliários), muitas vezes compete ao Estado subsidiar parte da produção de moradias, através da produção direta, do financiamento aos construtores e promotores imobiliários ou da concessão de créditos acessíveis aos mais pobres e para as camadas de rendimentos médios da população. Esse foi o caso do Brasil entre 1964 e 1986, quando o Estado articulou os elementos necessários à obtenção de recursos para o financiamento habitacional (produção e consumo), através de criação do Sistema de Financiamento Habitacional e do Banco Nacional da Habitação (BNH). Os recursos para o SFH seriam provenientes, principalmente de uma contribuição compulsória de empresários e trabalhadores, o Fundo de Garantia por Tempo de Serviço (FGTS), instituído em 1967, e da caderneta de poupança, que conformaria o Sistema Brasileiro de Poupança e Empréstimos (SBPE), responsável pelo financiamento de imóveis para a população de rendimentos médios.

As ações regulatória e produtiva do Estado entraram em colapso na década de 1980, devido ao descontrole inflacionário do período e ao escasseamento das fontes de recursos do sistema, o que comprometeu a capacidade de financiamento do setor habitacional a partir dessa década.

Com o colapso final desse sistema em 1986 (representado pela extinção do $\mathrm{BNH}$ ), se inicia um tortuoso processo de reestruturação do financiamento do setor imobiliário. Em 1997 foi criada a Lei 9.514, aprovada pelo Congresso Nacional a partir de proposta de lei da Associação Brasileira de Entidades de Crédito Imobiliário (ABECIP), que estabeleceu o Sistema Financeiro Imobiliário (SFI), sistema de financiamento complementar ao SFH (que não deixou de existir). Foram então realizadas inovações no financiamento imobiliário nacional, com a criação de instrumentos de securitização imobiliária, ou seja, instrumentos que possibilitavam a transformação de bens imóveis em títulos mobiliários, como os Fundos de Investimento Imobiliários e os Certificados de Recebíveis Imobiliários (CRIs). A lei que criou o SFI introduziu também um novo veículo legal denominado Companhia Securitizadora de Créditos Imobiliários, sociedades com propósitos de fazer a securitização ${ }^{5}$ dos recebíveis imobiliários através da emissão dos CRIs, títulos imobiliários equivalentes a debêntures.

\footnotetext{
${ }^{5}$ Vendrossi (2002:21) define securitização como a "emissão de títulos mobiliários com vínculo em um determinado ativo". Para um estudo mais detalhado da securitização de recebíveis imobiliários, ver Vendrossi, 2002.
} 
São inovações que buscam articular o setor imobiliário com o mercado financeiro, estabelecendo um processo de desintermediação bancária para o financiamento da produção, ao mesmo tempo em que oferecem possibilidades de ganhos financeiros aos investidores. $\mathrm{O}$ mecanismo da securitização amplia as possibilidades de captação de recursos e acesso a financiamento aos "originadores" desses créditos (as empresas que produzem os ativos a serem securitizados, como as incorporadoras, construtoras etc.), dando acesso direto ao mercado de capitais, reduzindo, teoricamente, os custos e riscos da captação. Também a securitização possibilita um giro maior do capital das empresas, que receberiam dos investidores os recursos e repassariam para estes seus créditos representados pelos ativos. Por exemplo, uma incorporadora, após vender as unidades de um edifício por ela construído, pode securitizar os contratos de compra e venda financiados a prazo aos compradores e vendê-las no mercado. Receberia de volta em um prazo mais reduzido o capital utilizado para financiar a venda, e poderia reinvestir esse capital em outra atividade ou em outro empreendimento. Os investidores que compraram os títulos, por sua vez, passariam a receber os juros e a amortização das dívidas, chamados de "recebíveis".

Os FIIs foram criados em junho de 1993, pela Lei 8.668, e regulamentados pela CVM em janeiro do ano seguinte, ano em que foi lançado o primeiro FII, o Memorial Office Building, na cidade de São Paulo. Atualmente já estão em funcionamento cerca de 60 fundos, com um patrimônio de cerca de R \$1,4 bilhão ${ }^{6}$, e movimentam, por ano, cerca de R\$ 600 milhões. Até 1999, os principais investidores nos FIIs eram os grandes fundos de pensão e investidores institucionais. Somente a partir desse ano é que se buscou atrair os pequenos e médios investidores, com o lançamento de fundos com cotas de valor unitário mais baixo. A vantagem, do lado do investidor, seria a de que os FIIs tornam o investimento imobiliário acessível aos pequenos e médios investidores, através do fracionamento da emissão de cotas, também dá maior mobilidade às transações de investimento imobiliário, evitando os trâmites de escrituras, certidões etc.

Os projetos que são alvo dos FIIs são variados, desde shopping centers e parques temáticos a hospitais, de edifícios de escritórios e galpões industriais a conjuntos habitacionais e condomínios de alto padrão. Mas são projetos que visam um rendimento para os investidores

${ }^{6}$ Ver http://www.fundoimomiliario.com.br. 
que está acima das possibilidades oferecidas pelo mercado de habitação popular ou econômica.

Já os Certificados de Recebíveis Imobiliários (CRIs) foram criados com a lei 9.514 de 1997, que criou o SFI. Segundo essa lei, "o Certificado de Recebíveis Imobiliários - CRI é um título de crédito nominativo, de livre negociação, lastreado em créditos imobiliários e constitui promessa de pagamento em dinheiro". De forma equivalente a uma debênture, o CRI pode ser colocado no mercado através de uma emissão pública (títulos postos à venda junto ao mercado, sem necessidade de destino específico) ou de uma emissão privada (específica para determinados investidores já acertados).

Além de ser fonte de financiamentos, os CRIs podem, com a formação de um mercado secundário de negociação desses créditos, se transformarem em uma nova fonte de ganhos com especulação com papéis.

Baseando-se em dados da Comissão de Valores Mobiliários (CVM), estima-se que foram emitidas, até 2002, cerca de R \$ 340 milhões em CRIs (VENDROSSI, 2002). Desse total, 50\% corresponderiam a operações relativas ao mercado de imóveis residenciais.

A instituição dos CRIs como fonte de financiamento imobiliário visa a atender aos interesses da produção habitacional de mercado e de outras atividades imobiliárias (produção de imóveis comerciais, industriais, escritórios de alto padrão), sendo que os CRIs seriam, em sua maior parte, dirigidos para o mercado habitacional, pois se tratam de operações de longo prazo com fluxo de caixa certo, além de serem suficientemente pulverizados para evitar maiores riscos para os investidores.

A criação dos FIIs e CRIs marca a formalização de um processo simultâneo de crescente mercantilização da política habitacional e de financeirização do mercado imobiliário.

A hipótese trabalhada no presente artigo é a de que os FIIs e CRIs são ativos financeiros que se valorizam através não só da produção imobiliária, mas também, e em grande medida, da localização do imóvel no tecido urbano. Dessa forma, a renda fundiária faria parte dos rendimentos pagos aos investidores, na medida em que tais rendimentos teriam uma relação direta com o lugar ocupado pelo imóvel no urbano. No 
próximo item, será analisada a localização desses tipos de ativos no município de São Paulo como forma de relacionar a sua constituição com as áreas de valorização fundiária urbanas.

\section{A espacialidade dos Flls e CRIs em São Paulo}

Com a securitização imobiliária, a questão da extração da renda fundiária é de certa forma absorvida e mascarada no processo de valorização imobiliário-financeira dos ativos, transformando-se em direitos de receber uma renda, obscurecida sob a forma de juros provenientes de um ativo imobiliário fragmentado em títulos, com a mediação do mercado financeiro. Não é mais a propriedade de um bem imóvel que garante a renda, mas sim a propriedade do direito de extrair, a partir de um empréstimo, além da renda presente no imóvel, os juros do capital adiantado. Juros e renda aparentemente se confundem. Dessa forma, saber a localização no espaço urbano dos imóveis securitizados pode indicar o papel da renda fundiária, pois estes imóveis devem se localizar nas áreas mais valorizadas das cidades para render o máximo possível.

Em levantamento realizado junto à Comissão de Valores Mobiliários (CVM) e empresas ligadas à emissão desses papéis, pôde-se perceber que a grande maioria dos FIIs e dos CRIs lançados na cidade de São Paulo a partir de 1994 concentram-se no chamado "vetor sudoeste" do município de São Paulo. De 46 FIIs existentes em 2004, 36 encontram-se nesse setor. E dos 40 CRIs consultados, 24 estão situados nessa área. Ou seja, a percepção dos agentes de que a localização dos empreendimentos é fundamental para seu maior retorno faz com que seus interesses se voltem para as áreas mais valorizadas das cidades. O Mapa $1^{7}$ apresenta uma representação dos valores do solo no município de São Paulo, e pode-se observar que a área do "vetor sudoeste" da cidade constituiu o principal eixo de valorização imobiliária. O mapa apresentado em seguida, e elaborado a partir dos dados pesquisados, mostra a localização dos FIIs e dos CRIs no município de São Paulo, bem como dos imóveis pertencentes a Fundos de Pensão na capital paulista ${ }^{8}$.

\footnotetext{
${ }^{7}$ Para detalhes metodológicos para a produção do mapa em questão ver Machado, 2004.

${ }^{8}$ Os imóveis pertencentes aos Fundos de Pensão foram incluídos, apesar de não serem tratados em detalhe no presente artigo, pois trata-se de outra forma de inter-relação entre o setor imobiliário e o mercado financeiro, na medida em que tais instituições buscam rendimentos financeiros através da exploração da propriedade imobiliária. Para um estudo sobre a atuação dos Fundos de Pensão nas áreas de valorização imobiliária em São Paulo,
} 


\section{Mapa 1. Valor Venal da Terra no Município de São Paulo}

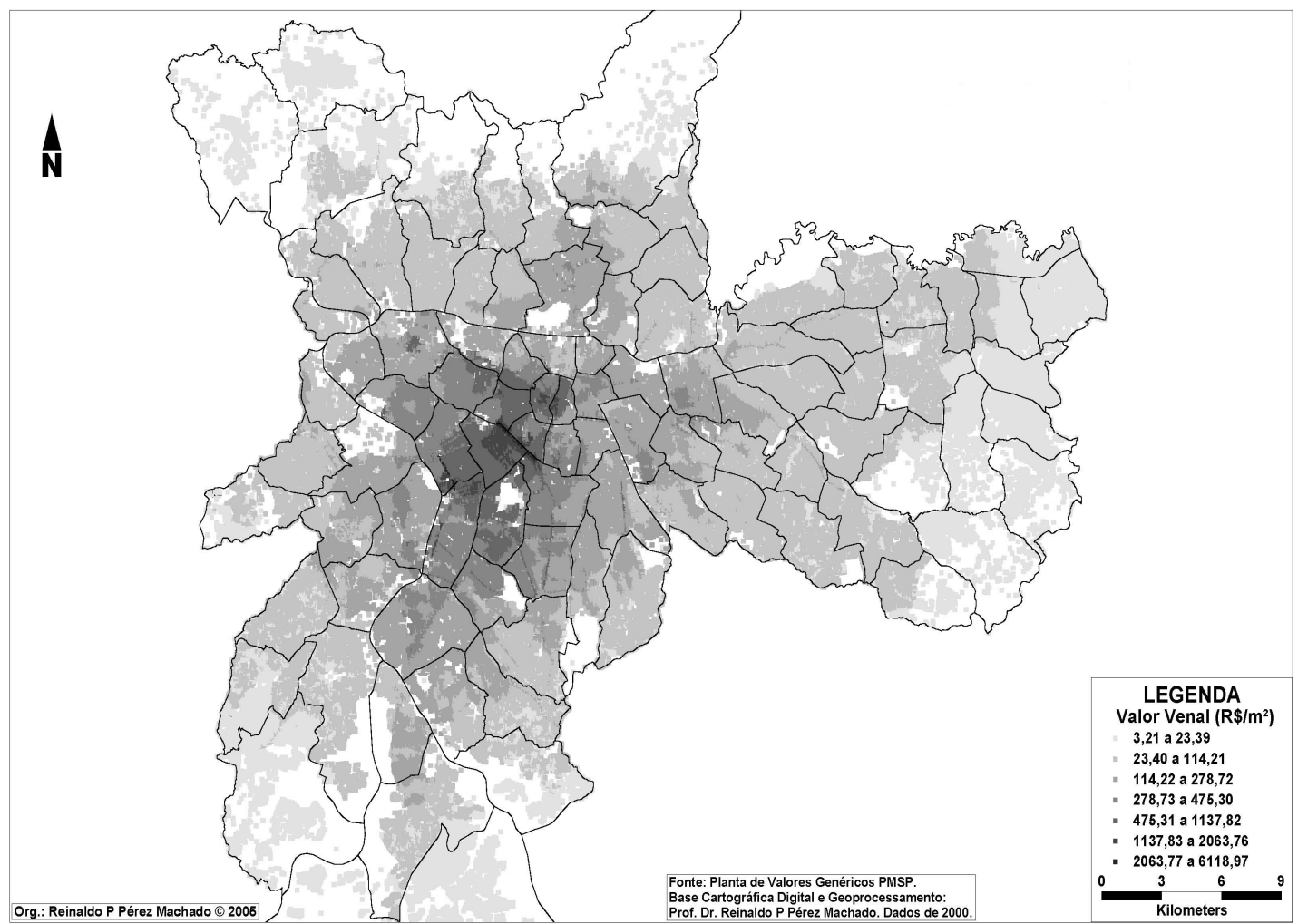

ver Fix, 2001. 
Mapa 2. Localização dos FIIs, CRIs e Imóveis de Fundos de Pensão no Município de São Paulo

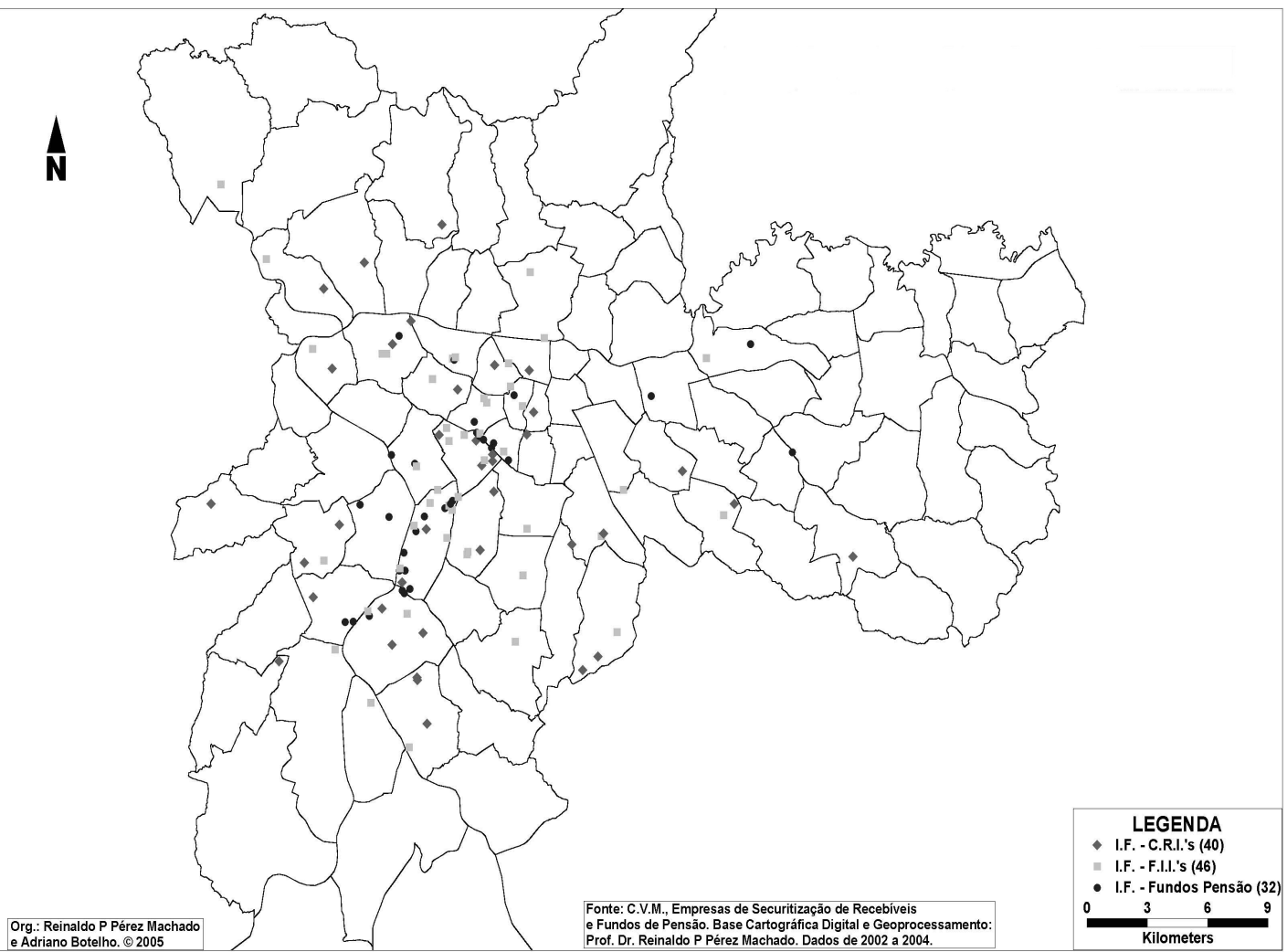

Observa-se, comparando os dois mapas, uma forte correlação entre a ação dos empreendimentos ligados às instituições financeiras com as áreas de maior valor venal, algo "natural" se for levado em consideração o fato de que tais instituições - representadas pelos Fundos de Pensão (FPs), pelos Fundos de Investimento Imobiliário e pelos imóveis securitizados através de CRIs - representam parte da fração mais sofisticada do setor imobiliário (tanto em termos de produção dos imóveis quanto ao mercado consumidor a que se destinam) e contam com os recursos do capital financeiro, potencializando sua ação no mercado imobiliário.

À análise visual pode ser somada uma análise estatística da freqüência das observações. Utilizando-se como limites de intervalo os mesmos usados para a delimitação das classes de valor venal do solo do 
Mapa 2, tem-se a distribuição de freqüências para as Instituições Financeiras reproduzida na tabela 1.

Tabela 1. Distribuição de Freqüência dos Imóveis de Instituições Financeiras por Classes de Valor Venal da Terra no Município de São Paulo - 2004

Classe (R\$)Freqüência0 - 3,2003,21 - 23,39223,4 - 114,2124114,22 278,7237278,73 - 475,3114475,32 -1137,82261137,83 - 2063,7682063,76 - 6118,977

Elaborado a partir de dados obtidos junto à CVM, Empresas de Securitização de Recebíveis e Fundos de Pensão, no período entre 2002-2004.

A maior parte dos estabelecimentos situa-se na faixa entre 114,22 a $1.137,82 \mathrm{R} \$ / \mathrm{m}^{2}$ (77 imóveis, representando $65,25 \%$ da amostra). Cerca de $6,7 \%$ dos imóveis situam-se na faixa de preço entre $1.137,83$ a $2.063,76$ $\mathrm{R} \$ / \mathrm{m}^{2}$ e outros $6 \%$ situam-se na faixa entre $2.063,77$ e $6.118,97 \mathrm{R} \$ / \mathrm{m}^{2} . \mathrm{Na}$ faixa inferior de valores, $1,7 \%$ dos imóveis situa-se numa faixa de valor entre 3,21 e 23,39 R $\$ / \mathrm{m}^{2}$ (trata-se de imóveis utilizados com fins industriais e de logística pertencentes ao FII Europar, localizados em áreas mais distantes do centro do município). E $20 \%$ dos imóveis situam-se na faixa entre 23,4 e $114,21 \mathrm{R} \$ / \mathrm{m}^{2}$. A distribuição de freqüências pode ser visualizada no gráfico 1 .

Gráfico 1. Distribuição de Freqüência dos Imóveis de Instituições Financeiras por Intervalo de Valor Venal da Terra no Município de São Paulo - 2004 


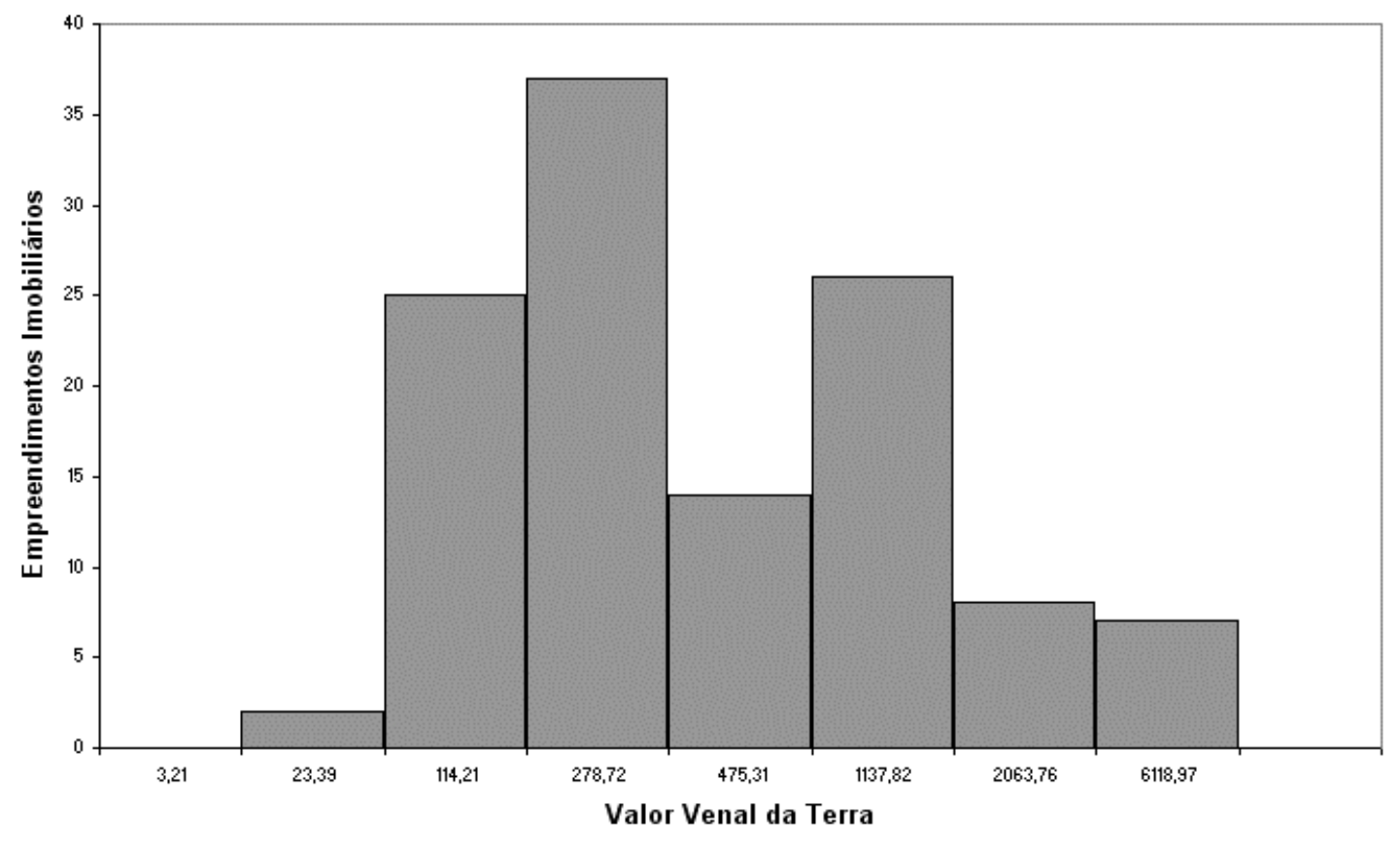

Elaborado a partir de dados obtidos junto à CVM, Empresas de Securitização de Recebíveis e Fundos de Pensão, no período entre 2002-2004

Dessa forma, conclui-se que quase $80 \%$ dos imóveis pertencentes às Instituições Financeiras que atuam no mercado imobiliário paulistano diretamente situa-se numa faixa de valores da terra no Município de São Paulo que pode ser considerada como média, média-alta e alta ${ }^{9}$. A análise dos dados obtidos confirmaria que os agentes imobiliários ligados às Instituições Financeiras atuam preferencialmente nas áreas de maior valor venal da terra, pois buscam a valorização máxima dos empreendimentos como forma de prover o pagamento de dividendos (nos quais confundemse renda, juros e lucros) aos seus acionistas ou cotistas.

Essa ação dos agentes imobiliários associados ao mercado financeiro interfere na dinâmica urbana, na medida em que as áreas já valorizadas e

${ }^{9}$ Considera-se como o intervalo entre zero e $114,21 \mathrm{R} \$ / \mathrm{m}^{2}$ como correspondente à faixa de valores baixos. Entre 114,22 e 475,31 R $\$ / \mathrm{m}^{2}$ como valores médios, entre 475,32 e $1.137,82 \mathrm{R} \$ / \mathrm{m}^{2}$ como médios-altos e, finalmente, acima de $1.137,83 \mathrm{R} \$ / \mathrm{m}^{2}$ como altos valores dos terrenos. 
privilegiadas em termos de infra-estrutura urbana atraem novos investimentos, consolidando a hierarquização dos espaços fragmentados do urbano e contribuindo para a crescente segregação sócio-espacial, como será analisado no próximo item.

\section{A renda fundiária e a hierarquização, fragmentação e segregação da sociedade no espaço urbano}

A dinâmica de acumulação capitalista contemporânea é marcada por um maior peso do setor terciário, e particularmente do setor financeiro, o que contribui para uma produção do espaço ligada a estratégias monopolistas, com maior participação do capital financeiro nos empreendimentos imobiliários para a execução cada vez mais freqüente dos chamados megaprojetos e dos condomínios-fortaleza. Ao mesmo tempo, há o fenômeno do aumento do desemprego, do subemprego e da economia informal. Tal processo é observado na maior parte dos países capitalistas, do centro e da periferia do sistema. No Brasil, uma das conseqüências desse fenômeno é a precarização da moradia de grande parte dos trabalhadores (com o aumento do número de favelados e moradores de cortiços), o que pode ser observado explicitamente nas grandes metrópoles nacionais, como é o caso de São Paulo.

Segundo Teresa Pires do Rio Caldeira (2000), a São Paulo do final dos anos 90 seria mais diversa e fragmentada do que era nos anos 70. A oposição centro-periferia continuaria a marcar a cidade, mas a São Paulo de hoje seria uma região metropolitana mais complexa, que não poderia mais ser mapeada pela simples oposição de rico versus pobre, sendo, antes de tudo, uma cidade de muros com uma população obcecada por segurança e discriminação social.

A cidade "ilegal", forjada a partir da década de 1940, cujo processo de formação de periferias se intensificou na década de 1960, continua a representar a maior parte da área urbanizada e é o local de moradia da maioria dos habitantes de São Paulo. Ainda havia 105.102 lotes irregulares no município no ano 2000 (SPOSATI, 2001), ocupando mais de 52 milhões de metros quadrados, concentrados nas áreas de mananciais e de proteção ambiental no extremo sul da capital paulista.

Já a expansão urbana da cidade "legal" das duas últimas décadas passou a ser determinada por grupos empresarias que se deslocam para o quadrante sudoeste do município, evadindo-se do centro tradicional, 
deixando ali prédios desocupados. O velho centro torna-se, então, um problema social, engendrando associações e projetos "de revitalização" (com o apoio do Estado), projetos que envolvem importantes interesses do capital imobiliário e financeiro (FRUGGOLI, 2000).

A desregulamentação do mercado imobiliário e o predomínio das "forças do mercado" no setor, que atuariam segundo uma lógica financeira, teriam como conseqüência 0 aumento da segregação, fragmentação e hierarquização do espaço urbano, o que reforçaria as tendências históricas presentes na metrópole paulista. Segundo Melo (1990), a forte elitização do mercado imobiliário que se concentra nos estratos superiores de renda é caracterizada por sua concentração geográfica nas áreas mais valorizadas e que contam com as melhores características de infra-estrutura urbana. No caso de São Paulo trata-se do chamado "vetor sudoeste", área que engloba as áreas mais valorizadas da cidade ou em forte processo de valorização (como as áreas das Avenidas Paulista, Faria Lima, Eng. Luis Carlos Berrini, das Nações Unidas etc.). Em 2002, 63\% dos lançamentos de alto padrão que ocorreram na Grande São Paulo concentraram-se nos distritos de Moema (597), Campo Belo (488), Morumbi (406), Jardins (23) e Alto de Pinheiros (130) (LAGE, 2003). Isso significa que o vetor sudoeste se expandiu em direção ao sul do município, mantendo o padrão de concentração das camadas de renda mais alta da população nessa área da cidade, apesar de uma maior presença aí de favelas e loteamentos irregulares.

A união entre o setor imobiliário e o mercado financeiro possui importantes conseqüências para a estruturação das cidades em áreas de segregação e fragmentação espacial, pois as cidades, e particularmente seus componentes residenciais, moldam-se pela maneira como são financiados (HUCHZERMEYER, 2004). A terra que tardiamente se tornou mercadoria na história brasileira, recentemente entrou no circuito de valorização do capital financeiro, através de instrumentos como os CRIs's e os FIIs. O mercado imobiliário complexifica-se com essa maior aproximação com o capital financeiro, acentuando o processo de fragmentação do espaço urbano, principalmente através da construção de grandes empreendimentos residenciais, terciários ou comerciais sem relação com o entorno imediato, separados por barreiras físicas e sociais.

Dessa forma, a constituição de um mercado imobiliário unido estreitamente ao capital financeiro atua no sentido de aprofundar as distâncias existentes entre as distintas classes e frações de classes sociais, pois são apenas pequenos grupos privilegiados os que podem ter acesso à 
produção imobiliária desse mercado mais restrito. Tal distanciamento é acentuado quando se considera a atual política habitacional e seu financiamento voltado para uma crescente desregulamentação no Brasil.

É possível constatar, através da análise dos dados apresentados no item anterior, que a produção do espaço no município de São Paulo tornou-se mais fragmentada, hierarquizada e segregada devido à ação dos agentes imobiliários urbanos, ação essa que possui certa correspondência com o tipo de relação estabelecida com o capital financeiro e com o mercado de capitais. Através dos dados analisados, constata-se que a ação dos agentes imobiliários ligados às Instituições Financeiras (Fundos de Investimento Imobiliário, Empresas de Securitização de Recebíveis Imobiliários e Fundos de Pensão) concentra-se nas áreas mais valorizadas do urbano e concretiza-se através de empreendimentos de alto padrão, ligados tanto ao comércio (shopping centers), à gestão do capital (centros empresariais e grandes edifícios de escritórios) e à moradia. Dado o grande volume de capital empregado nesses empreendimentos e às suas proporções, pode-se considerar que correspondem a legítimos representantes do capital monopolista, cuja ação materializa-se em uma maior homogeneização do espaço e de sua fragmentação, na medida em que tais empreendimentos cada vez possuem menos relação com seu entorno imediato, constituindo-se em verdadeiras ilhas no urbano. Mas são ilhas com uma arquitetura bem característica e com uma padronização sócio-econômica que exclui como usuários as camadas da população de rendimentos médios e baixos.

Deve-se levar em consideração que os novos instrumentos de captação de recursos (FIIs e CRIs) ainda estão em uma fase inicial no Brasil, com uma atuação ainda tímida, mas que possui importantes potencialidades de se transformar em uma importante forma de obtenção de recursos para o setor imobiliário. Trata-se, porém, de uma solução de mercado, que não pode ser considerada pelo poder público, nem pelos agentes imobiliários urbanos como a única solução para o financiamento imobiliário tendo em vista a realidade sócio-econômica da grande maioria da população que não pode entrar nesse mercado nos termos colocados atualmente. É necessário que outras soluções existam, sob o risco de que os processos de segregação sócio-espacial se acentuem até limites inimagináveis nas metrópoles brasileiras. 


\section{A RENDA FUNDIÁRIA URBANA: UMA CATEGORIA DE ANÁLISE AINDA VÁLIDA}

Resumo: Renda fundiária urbana é uma categoria pouco explorada pela maioria dos estudos mais recentes sobre o urbano. Porém, essa categoria oferece uma possibilidade de abordagem do urbano que permite a análise de fenômenos importantes, como a hierarquização dos usos do solo, o papel do setor imobiliário para a acumulação do capital e para a reprodução das relações de produção capitalistas, além de ser importante para o entendimento do processo de segregação sócio-espacial e fragmentação do espaço no urbano. Assim, levando-se em consideração os estudos passados e as dificuldades que ainda hoje permanecem, a questão da renda fundiária é retomada no presente artigo. Como forma de viabilização da análise da questão da renda fundiária urbana foi realizado um estudo de caso sobre uma modalidade de intervenção no urbano por parte do setor imobiliário em aliança com o mercado financeiro no município de São Paulo: os Fundos de Investimento Imobiliário e a Securitização de Recebíveis Imobiliários.

Palavras-chave: Renda Fundiária Urbana, Fragmentação, Segregação Sócio-Espacial, Urbano, Financiamento do Setor Imobiliário, Reprodução do Capital.

\section{THE URBAN LAND RENT: A CATEGORY OF ANALYSIS STILL VALID}

Abstract: Urban land rent is a category little explored by most recent urban studies. However, this category offers a possible approach for urban space that allows the analysis of relevant phenomena, like hierarchy in land use, the role of the real estate industry for capital accumulation and for reproduction of relationships in capitalist production, besides its importance in understanding the socio-spatial segregation and fragmentation process. In this sense, taking into account earlier studies and difficulties that still remain, this article aims to analyse the problem of land rent. To make this analysis possible, we present a case study about a kind of urban intervention by real estate agents in association with the finance market in the city of São Paulo: Real Estate Investment Funds and Real Estate Bonus.

Keywords: Urban Land Rent, Fragmentation, Socio-Spatial Segregation, Urban, Real Estate Financing, Reproduction of Capital. 


\section{BIBLIOGRAFIA}

ALQUIER, François (1971). Contribution à l'étude de la rente foncière sur les terrains urbains. In : Espaces et Sociétés n. 2. Paris: Anthropos, pp. 7587

CALDEIRA, Maria Teresa Pires do Rio (2000). Cidade de muros - crime, segregação e cidadania em São Paulo. São Paulo: Editora 34 / Edusp.

ENGELS, Friedich (1979). A questão da habitação. Belo Horizonte: Aldeia Global.

FINE, Bem (1988). Propriedade fundiária e renda da terra. In: Bottomore, Tom (editor), Dicionário do pensamento marxista. Rio de Janeiro: Jorge Zahar.

FIX, Mariana (2001). Parceiros da exclusão: duas histórias da construção de uma "nova cidade" em São Paulo: Faria Lima e Água Espraiada. São Paulo: Boitempo.

FRÚGOLI JR, Heitor (2000). Centralidade em São Paulo: Trajetórias, conflitos e negociações na metrópole. São Paulo: Cortez, Editora da Universidade de São Paulo.

HARVEY, David (1980). A Justiça Social e a Cidade. São Paulo: Hucitec.

(1990). Los limites del capitalismo y la teoría marxista, México: Fondo de Cultura Económica.

HUCHZERMEYER, Marie (2004). Subsídios habitacionais e segregação urbana: uma reflexão sobre o caso da África do Sul. In: Espaço \& Debates, v. 24 n. 45.

LAGE, Amarílis (2003). Desequilíbrio distancia bairros de SP. Folha de $S$. Paulo, Caderno Especial Imóveis, 19/01/2003, p. 2.

LEFEBVRE, Henri (1978). De lo rural a lo urbano. Barcelona: Ediciones Península.

(1999). A cidade do capital. Rio de Janeiro: DP\&A.

LIPIETZ, Alain (1974). Le Tribut Foncier Urbain. Paris : François Maspero. 
LOJKINE, Jean (1971). Y a-t-il une rente foncière urbaine? In : Espaces et Sociétés n. 2. Paris: Editions Anthropos, pp. 89-94.

Martins Fontes.

(1997). O Estado Capitalista e a Questão Urbana. São Paulo:

MACHADO, Reinaldo Paul Perez (2004). Isotimas: uma metodologia para a representação cartográfica do valor da terra e imóveis nas metrópoles latino-americanas utilizando técnicas de Geoprocessamento. In Carlos, Ana Fani Alessandri e Oliveira, Ariovaldo Umbelino de. Geografias de São Paulo: Representação e crise da Metrópole - São Paulo: Contexto, pp. 315-336.

MARTINS, José de Souza (1983). Os camponeses e a política no Brasil As lutas sociais no campo e o seu lugar no processo político. Petrópolis: Vozes.

(1996). O cativeiro da Terra. São Paulo: HUCITEC.

MARX, Karl (1989). O Capital, Livro III, Vol. 6. Rio de Janeiro: Bertrand Brasil.

MELO, Marcos André B. C. de (1990). Estruturação intra-urbana, regimes de acumulação e Sistemas Financeiros da Habitação: Brasil em perspectiva comparada. In: Espaço \& debates, n ${ }^{\circ} 31$ - São Paulo: Neru.

OLIVEIRA, Ariovaldo Umbelino (1984). Renda da terra. In: ORIENTAÇÃO n. 5. São Paulo: Instituto de Geografia, Universidade de São Paulo, pp. 94-95, Out. 1984.

(1985). Renda da Terra Diferencial I e Renda da Terra Diferencial II. In: ORIENTAÇÃO n. 6. São Paulo: Instituto de Geografia, Universidade de São Paulo, pp. 93-104, Dez. 1985.

(1986). Renda da Terra Absoluta, Renda da Terra de Monopólio, Renda da Terra Pré-Capitalista, Preço da Terra. In: ORIENTAÇÃO n. 7. São Paulo: Instituto de Geografia, Universidade de São Paulo, pp. 77-85, Dez. 1986.

RIBEIRO, Luiz César Queiroz (1997). Dos cortiços aos condomínios fechados: as formas de produção da moradia na cidade do Rio de Janeiro. Rio de Janeiro: Civilização Brasileira.

SEABRA, Odette Carvalho de Lima (1987). Os meandros dos rios nos meandros do poder: Tietê e Pinheiros - Valorização dos rios e das 
várzeas na cidade de São Paulo. Tese de Doutorado. São Paulo: Departamento de Geografia, FFLCH - USP.

(1988). Pensando o processo de valorização e a geografia. In: Boletim Paulista de Geografia, n. 66. São Paulo: Associação dos Geógrafos Brasileiros, pp. 97-103, 1 Sem. 1988.

TOPALOV, Christian (1979). Análise do ciclo de reprodução do capital investido na produção da indústria da construção civil - Capital e propriedade fundiária. In: Forti, Reginaldo. Marxismo e urbanismo capitalista. São Paulo: Livraria Editora Ciências Humanas, p. 53-80.

Paris: Economica.

(1984). Le profit, la rente et la ville: Eléments de théorie.

VENDROSSI, Alessandro Olzon (2002). A securitização de recebiveis imobiliários: uma alternativa de aporte de capitais para empreendimentos residenciais no Brasil. Dissertação de Mestrado. São Paulo: Escola Politécnica, USP. 